\title{
THE PUBLIC REGULATION OF ECONOMIC RELATIONS IN THE MODERN STATE: THEORETICAL ASPECT
}

\author{
Vladimir E. Berezko \\ Moscow State Institute of International Relations of the Ministry of Foreign Affairs of the Russian Federation, \\ Moscow, Russian Federation
}

When people are well managed, they do not seek or desire any other freedom.

N. Machiavelli

Both Capital and Labor are not separate groups, they are partners.

Introduction: the economic sphere of society has always been of great interest and played a significant role in the functioning of society. In today's world, the problem of building the social state not only does not lose relevance, but also becomes more and more acute. In this regard, the purpose of the study was the public regulation of economic relations in the modern state and the economic aspects of the social state's being. Methods: the research methodology includes the systematic, comparative law method, the method of logical analysis, as well as the methods of exegesis and hermeneutics. Results: in the course of the analysis the fundamental nature of the social state principle the under modern conditions is substantiated. The economic activity of the public authorities and the realization of public interest are a necessary condition for the building of the social state. Conclusions: as a result of the study it is found that the role of the state power in building the social state is of fundamental importance. Without the public regulation of economic relations it is impossible to build the social state, to achieve the necessary level of welfare of the people and the prosperity of the country. The realization of public interest under a free market economy is not the suppression of freedom, but "the service" to it.

Key words: social state, social issue, law, state power, public regulation, economic relations.

Citation. Berezko V.E. The Public Regulation of Economic Relations in the Modern State: Theoretical Aspect. Legal Concept, 2019, vol. 18, no. 1, pp. 78-87. (in Russian). DOI: https://doi.org/10.15688/lc.jvolsu.2019.1.10

\section{ПУБЛИЧНО-ПРАВОВОЕ РЕГУЛИРОВАНИЕ ЭКОНОМИЧЕСКИХ ОТНОШЕНИЙ В СОВРЕМЕННОМ ГОСУДАРСТВЕ: ТЕОРЕТИЧЕСКИЙ АСПЕКТ}

\section{Владимир Эдуардович Березко}

Московский государственный институт международных отношений (Университет) МИД России, г. Москва, Российская Федерация

Когда людьми хорошо управляют, они не ищут и не желают другой свободы.

Н. Макиавелли

И Капитал, и Рабочая сила - не отдельные группы, они - партнеры. 
Введение: экономическая сфера жизни общества во все времена представляла собой огромный интерес и играла значительную роль в функционировании социума. В современном мире проблема строительства социального государства не только не теряет актуальности, но и становится все более острой. В связи с этим целью исследования стало публично-правовое регулирование экономических отношений в современном государстве и экономических аспектов бытия социального государства. Методы: методология исследования включает в себя системный, сравнительно-правовой метод, метод логического анализа, а также методы экзегетики и герменевтики. Результаты: в ходе проведенного анализа обосновывается фундаментальность принципа социального государства в современных условиях. Экономическая деятельность публичной власти, реализация публичного интереса представляется необходимым условием построения социального государства. Выводы: в результате исследования установлено, что роль государственной власти в построении социального государства имеет фундированное значение. Без публично-правового регулирования экономических отношений невозможно построение социального государства, достижения необходимого уровня благосостояния народа и процветания страны. Реализация публичного интереса в условиях рыночной экономики становится не подавлением свободы, а «служением» ей.

Ключевые слова: социальное государство, социальный вопрос, право, государственная власть, публично-правовое регулирование, экономические отношения.

Цитирование. Березко В. Э. Публично-правовое регулирование экономических отношений в современном государстве: теоретический аспект // Legal Concept = Правовая парадигма. -2019 . - T. 18, № 1. C. 78-87. - DOI: https://doi.org/10.15688/lc.jvolsu.2019.1.10

\section{Введение}

Социальное государство, безусловно, одно из величайших достижений человеческой цивилизации. Научное обоснование социального государства ознаменовало собой новую веху в истории человечества. Сегодня немыслима ни одна развитая страна, если она не является социальным государством, а государственное управление в ней не является социально эффективным, не решает насущные проблемы общества и каждого человека в отдельности.

\section{Исследование}

Необходимо отметить в этой связи, что автор работы не находится на позициях экономического детерминизма, когда экономика определяет в жизни общества все - государство и право в том числе. Но нельзя при этом игнорировать очевидный факт - без надлежащего развития экономики невозможно построение справедливого, конституционного государства, или - социального государства в широком смысле. Весьма актуальным в этой связи представляется вопрос о вмешательстве государства в экономику, а также - peшение социального вопроса ${ }^{1}$.

Современное понимание социального вопроса диктует и соответствующее осмыс- ление либеральной идеологии. В традиции «старого», «чистого» либерализма государству отводится незавидная роль - охранителя частной собственности, «ночного сторожа». Но парадокс заключается в том, что и в современном мире подобная - уже устаревшая и отвергнутая практически всеми развитыми странами - точка зрения продолжает существовать. Более того, ее апологеты упрямо продолжают противопоставлять власть и свободу, государство и рыночную экономику. Но исследование реальности, объективных экономических отношений в развитых странах приводит совсем к другим выводам [1, c. 3]. Ученые вполне справедливо отмечают, что роль крупных корпораций в современном мире стремительно растет [1, с. 7].

То же самое касается и отношения к такому важному аспекту развития экономики, как планирование. Апологеты экономической абсолютной «свободы» нередко всячески клеймят процесс планирования, который был едва ли не определяющим в советское время. С радикальной решимостью и одновременно - беззаботностью - от него поспешно отказались в начале 90-х гг. прошлого века. Таким же образом, кстати, в начале XX в. строили коммунизм. Между тем для специалистов совершенно очевидно, что подобный подход может привести к уничтожению самого управления как явления. Прозрение на- 


\section{ТЕОРИЯ И ПРАКТИКА ГОСУДАРСТВЕННО-ПРАВОВОГО РАЗВИТИЯ}

ступило, как всегда, совершенно неожиданно [3, с. 145]. Следует отметить, что данное замечание касается не только сферы планирования. В современном мире уже происходит новое осмысление фундаментальных ценностей демократии [6]. В этой связи интересна и следующая блестящая работа [4].

В определенной степени такой подход к экономике диктуется, прежде всего, публично-правовой природой государственной власти. Решение «общих дел» немыслимо без грамотного влияния государства на экономику как сферу общественной жизни, без публично-правового регулирования общественных отношений.

Речь, подчеркну, идет вовсе не о подавлении (или полном подчинении) частного интереса интересу публичному, а о разумном их сочетании. Совершенно очевидно, что с точки зрения частного интереса безработица выгодна, поскольку снижается стоимость рабочей силы. Но с точки зрения публичного интереса безработица является угрозой для стабильности государства как триединства территории, населения и власти. При огромной массе безработных риски для устойчивого развития государства возрастают многократно. Обозленный, не имеющий достойного дохода человек всегда может стать питательным материалом для радикальных пропагандистов, которые с удовольствием ответят ему на два извечных русских вопроса: «Кто виноват?» и «Что делать?».

Реализация частных интересов должна в совокупности вести к процветанию всего общества. И корень проблем в экономике и в других сферах общественной жизни по своей сути один - плохое управление. Еще Генри Форд называл этот фактор причиной «невезения» [21, с. 168].

Если вспомнить известную песню, то совершенно очевидно, что жизнь на знаменитом «острове невезения» вполне можно изменить к лучшему. Дело не только в понедельниках, а в наличии профессионалов в каждой сфере деятельности. Профессор Охотский так писал об этом: «Ведь хорошо известно, что происходит, когда министрами становятся коммерсанты, сенаторами - дискредитировавшие себя министры и губернаторы, когда электростанции возглавляют финансисты-самоуч- ки, колхозы - горожане, строительные компании - спортсмены, а спорт - дилетанты от бизнеса, когда информатизацией МПС занимается вчерашний шоумен, когда на должности чиновников попадают люди с фальшивыми дипломами» [18, с. 418].

Замечу, что задолго до профессора Охотского о подобном явлении высказывался и известный американский промышленник Генри Форд. Весьма интересна его мысль о том, кто отвечает за некачественное управление. Ответ простой - все общество, а не только конкретный предприниматель, который, к примеру, заменил квалифицированных работников на неквалифицированных [21, с. 326].

Примечательно, что современный бизнес часто наступает на те же грабли - во имя экономии фонда оплаты труда. А потом предприниматели и эксперты картинно удивляются очередному обрушению жилых и нежилых зданий. Хотя любому здравомыслящему человеку понятно, что работающие за нищенскую зарплату приезжие по определению не могут выдавать высококачественную продукцию...

Характерно, как тот же Форд оценивал причину бедности. Звучит, на первый взгляд, парадоксально, но только на первый взгляд. Именно в отсутствии «служения» - добавлю, именно публичному интересу, интересам всего общества, - и заключается, по мнению Форда, причина бедности. Цитата, на мой взгляд, вполне заслуживает того, чтобы привести ее полностью: «Первопричина бедности, как я это представляю, заключается в несоответствии между производством и распределением как в промышленности, так и в сельском хозяйстве - между источниками энергии и ее применением. Результаты подобной несоразмерности колоссальные расходы и убытки. На борьбу с этими убытками и должно быть направлено разумное руководство. До тех пор, пока правительство будет занято мыслями о деньгах, а не о служении и пользе, убытки будут постоянно расти. Прекратить этот рост под силу лишь людям дальновидным, а не близоруким, озабоченным своей выгодой и считающим бескорыстное служение привилегией альтруистов, не понимая, что это самая практичная вещь на свете» [21, c. 235]. 
Характерная черта мировоззрения Генри Форда - он настойчиво напоминает нам из начала XX в., что «служение» в его терминологии предполагает реализацию прежде всего публичного интереса, а не частного, который проявляется исключительно в стремлении к прибыли ${ }^{2}$. Что, кстати, совсем не стоит клеймить как нечто плохое и неприличное. Стремление к прибыли для предпринимателя так же естественно, как дождь осенью и снег зимой. Упрекать его за это - значит спорить с самой природой человека. Подчеркну, что интерес особенный, частный ни в коем случае не должен подавляться.

Роль денег в обществе вовсе не стоит переоценивать, считает Генри Форд. Он даже иронизирует по поводу изменения курсов валют: «Фут - это всегда двенадцать дюймов, но когда доллар равнялся доллару? Если бы торговец углем стал произвольно менять вес тонны, а молочник вместимость литра, а метр сегодня равнялся бы 82, а завтра 95 сантиметрам, народ быстро исправил бы это положение. Когда доллар не равняется доллару, а становится сначала 65-центовым долларом, потом 50-центовым, потом 47-центовым (как раз то, что происходило с чудесными старыми американскими золотыми и серебряными долларами), какой смысл причитать о “дешевых деньгах", “обесцененных деньгах"? Доллар, который всегда равняется 100 центам, нам необходим так же, как фунт, равняющийся шестнадцати унциям, и ярд, в котором ровно тридцать шесть дюймов» [21, с. 229].

Переход, по словам Генри Форда, к счастливому и справедливому обществу невозможен без счастья отдельного человека. Известный американский промышленник убежден, что и отдельный человек становится счастливым, когда «переходит от собственнических интересов к служению людям... Вместе с ним вперед идет и мир!» [21, с. 347].

Подчеркну, что замечание Форда о «самой практичной вещи на свете»- вовсе не метафора. Он указывает на фундаментальные законы бытия и ведет речь о вполне конкретной и осязаемой прибыли. Но эта прибыль является не сиюминутной, а прибылью в стратегической перспективе, прибыли, которая в итоге дает обществу и конкретному индивиду гораздо больше, нежели сиюминутный ин- терес. И в этом смысле «служение», как реализация публичного интереса посредством реализации интереса частного, особенного, действительно заслуживает особого внимания в современной практике государственного строительства и государственного управления.

Сейчас, в начале XXI в., когда все громче звучат слова о социальной ответственности бизнеса [7], слова Форда как никогда актуальны. Главная проблема - найти разумный баланс между личным и общественным, между частным и публичным интересом в деятельности каждого предпринимателя. Форд по этому поводу писал: «Капитал, не способствующий созданию лучших рабочих мест и лучших условий труда, более бесполезен, чем песок, он не выполняет свою наиважнейшую и наисвятейшую функцию. Основная цель использования капитала - не просто делать деньги, а делать их для того, чтобы приносить больше пользы и совершенствовать окружающий мир» [21, с. 247].

Кстати, отчасти мысль Форда о «служении» подтверждают и исследования блестящих современных экономистов. Так, профессор Катасонов по этому поводу писал: «Люди дохристианской эпохи чутко улавливали простую мысль: деньги - это некое общественное достояние, которое не должно превращаться в средство накопления богатства, а выполняет роль “крови", циркуляция которой в хозяйстве обеспечивает его нормальное функционирование» [10, с. 15]. Весьма критично профессор Катасонов оценивает и схему currency board валютного управления [9, с. 9].

В современном мире, как показывает практика, наиболее востребованной является модель социальной рыночной экономики, которая в разных ипостасях присутствует во всех развитых странах планеты. Государственное регулирование экономики фактически не оспаривается ни в одном из этих государств. Однако именно в России до сих пор пытаются поддерживать идеи «старого» либерализма, отрицающего роль государства и государственной власти в регулировании экономических отношений.

Следует отметить, что ситуация в веке XXI просто поразительно напоминает реалии России XIX в. и начала XX столетия. Но и тогда уже были ученые, которые полагали 


\section{ТЕОРИЯ И ПРАКТИКА ГОСУДАРСТВЕННО-ПРАВОВОГО РАЗВИТИЯ}

весьма разумным вмешательство государства в экономические отношения. Например, следует отметить в этой связи труды выдающегося русского юриста Павла Ивановича Новгородцева. Он понимал под «социализмом» вмешательство государства в экономику, публично-правовое регулирование экономических отношений. И относился к этому весьма позитивно [16, с. 225-226].

Павел Иванович Новгородцев всегда с большим почтением и уважением относился к своему учителю - Борису Николаевичу Чичерину. Но при этом справедливо критиковал его отрицательное отношение к идее социального государства. Следует отметить, что Чичерин выступал как непримиримый критик социалистических идей [26, с. 182].

П.И. Новгородцев, в свою очередь, весьма справедливо отмечал, что равенства следует достигать, прежде всего, в возможностях, которыми обладает индивид. Иными словами - обеспечить функционирование «социальных лифтов», дать каждому человеку возможность изменить свою жизнь.

Воспользуется он этой возможностью или нет - вопрос совершенно другой. Важно, чтобы такая возможность у него была. П.И. Новгородцев писал по этому поводу: «Для теоретиков старого индивидуализма представлялось неизбежным, что подобное расширение приведет непременно к равенству материальному или, говоря определеннее, к принудительному уравнению, сопровождающемуся полным подавлением свободы. Между тем равенство исходного пункта не только не исключает свободы, но напротив предполагает ее...» [15, c. 220].

Участие государства в экономической жизни общества диктуется не только необходимостью решения социального вопроса. Государство является, по сути, единственным субъектом, способным осуществлять крупномасштабные проекты - например, освоение космоса - по той причине, что обладает возможностями привлекать самые разнообразные ресурсы для решения поставленной задачи. Морис Ориу указывал, что «...по своему бюджету и по всем своим публичным финансам государство само является крупнейшим финансистом» [17, с. 405]. Понятно, что здесь мы не сравниваем беднейшие африкан- ские страны и мощные транснациональные корпорации. В последних, кстати, по мнению серьезных экономистов, очень эффективно действуют и директивное планирование, и административно-командная система $[11$, с. $29-$ 30] - все то, что долгое время у нас подвергается жесточайшей критике...

Современные правоведы также отмечают, что национальные государства для транснациональных корпораций представляют только помеху: «Транснациональным корпорациям... стало фактически не нужнно общество как какая-то организация представления и защиты интересов подавляющей массы наемных работников и их семей. Ранее им мешало государство, теперь мешает национальное общество» [1, с. 88].

Главный спор по поводу того, как должна организовываться экономическая сфера жизни общества, всегда разворачивается между сторонниками рыночной экономики и «противниками» таковой. На самом деле такой спор в известной мере бесперспективен, по той простой причине, что чистая рыночная экономика направлена на реализацию исключительно частного интереса. Но в нормальном обществе необходимо публично-правовое регулирование экономики, как выше указывал П.И. Новгородцев, и, соответственно, реализация интереса публичного, достижение процветания всего общества.

Для современных исследователей совершенно очевидно, что следует избегать противопоставления социалистических учений и концептуальных теорий рыночной организации народного хозяйства, или - социализма и капитализма [2, с. 247-248].

Желание устранить государство из экономической сферы и наивно, и утопично одновременно [2, с. 225]. Известный немецкий экономист и государственный деятель (одно время он был Федеральным канцлером ФРГ) Людвиг Эрхард справедливо указывал, что низведение государства в экономике до положения «ночного сторожа» совершенно ненаучно и выходит за границы здравого смысла. Подобный «старолиберальный» подход вполне может привести к краху и самой либеральной идеи: «Современное и сознающее свою ответственность государство просто не может себе позволить еще раз вернуться к 
роли “ночного сторожа". Эта неверно понимаемая свобода как раз была тем, что привело в могилу свободу и свободный строй» $[28$, c. 226$]$.

Л. Эрхард выступал весьма последовательным сторонником вмешательства государства в экономику. Одна из главных задач, по его мнению, - борьба государства против монополий. Эрхард в этой связи писал: «Если государство спасует в этой области, - то вскоре можно будет распрощаться с "социальным рыночным хозяйством"» [28, с. 15].

При этом апологеты «свободного рынка» - те, кто, по сути, возводит его в абсолют, придерживаются радикального понимания рыночной экономики, крайне негативно относятся к любым, даже самым легким намекам на социалистические учения [24, с. 114].

У Фридриха фон Хайека совершенно очевиден односторонний подход к социалистической идее. Он видит там исключительно «рабство» и «коллективизм», фактически рассматривая эту идею в ее радикальном, крайнем выражении - словно тотальный коммунизм в духе первого проекта идеального государства у Платона, где, напомню, предусмотрена даже общность жен и детей. И это весьма напоминает коммуны, возникшие в Советской стране после 1917 года. Правда, в 30-е гг. отношение власти к коммунам поменялось на противоположное, особенно - после критики в Отчетном докладе на XVII съезде ВКП(б) в адрес «левацких головотяпов»...

Ф. Хайек собственного одностороннего подхода не замечает и критикует социализм увлеченно и жестко: «Парадокс заключается в том, что тот самый социализм, который всегда воспринимался как угроза свободе, и открыто проявил себя в качестве реакционной силы, направленной против либерализма Французской революции, завоевал всеобщее признание как раз под флагом свободы» [22, с. 49]. Как уже говорилось выше, этот парадокс при разумном сочетании публичного и частного интереса (то, что Форд называет «служением») перестает быть парадоксом и в итоге приводит к процветанию всего общества.

Резко негативная оценка Хайеком коллективизма - вполне в духе «старого» либерализма - приводит и к отрицанию сильного государства как созидающей субстанции: «Не существует большего заблуждения, чем общепринятая формула историков, которые представляют появление сильного государства как кульминацию культурной эволюции: оно столь же часто служило признаком ее конца» [25, с. 60].

Фундаментальная причина подобного подхода скрывается в «старом» либерализме австрийского экономиста, который упорно противопоставляет индивида и общество $[23$, с. 50$]$.

Авторитетные экономисты вполне определенно высказывались еще во второй половине прошлого века, что управленческая деятельность стала практически определяющей в функционировании крупных производственных форм [19, с. 34].

Следует особо подчеркнуть, что публично-правовое регулирование экономических отношений приобретает особое значение именно в период модернизационных изменений в народном хозяйстве, в период проведения необходимых для дальнейшего развития реформ.

Современные исследователи - например, известный военный историк Мартин ван Кревельд - отмечают уникальность китайского опыта по модернизации экономики. В Поднебесной избежали провального позднесоветского опыта по ослаблению власти с началом экономических либеральных реформ [13, c. 459].

Здесь, на мой взгляд, необходимо отметить следующее. Причина китайского успеха проста. Во всех других коммунистических странах - или, по крайней мере, в подавляющем большинстве из них - и, к великому сожалению, в нашем Отечестве - начинали на практике не с либеральных мер, не с расширения сферы свободы в экономике и других сферах общественной жизни, а с масштабного ослабления политической власти. Россия в двух разных ипостасях - Российской империи и СССР - в XX в. дважды наступила на одни и те же грабли. Между тем, как отмечали крупнейшие русские специалисты в области государственного права, власть в период реформ должна быть обязательно сильной, чтобы надлежащим образом провести задуманные либеральные реформы. Именно по этому 


\section{ТЕОРИЯ И ПРАКТИКА ГОСУДАРСТВЕННО-ПРАВОВОГО РАЗВИТИЯ}

пути пошел Китай, и сегодня его успехи уже всем очевидны.

Мог ли Советский Союз пойти тем же путем? Политический теоретик Джон Грей дает положительный ответ на этот вопрос [5, с. 109].

Те методы реформ, которые использовались в «новой» России, были попросту неэффективны и не имели необходимого научного обоснования. Если, конечно, не считать таковым уже упоминавшийся «старолиберальный» подход в экономике, что для конца XX в. уже просто архаика ${ }^{3}$. Джон Грей по этому поводу высказался весьма точно и определенно: «Вместо того, чтобы способствовать росту частного сектора в посткоммунистических странах, “шоковая терапия" скорее способна задушить его в колыбели» [5, с. 118].

Это, кстати, и произошло в России в 90-е годы. Сам частный сектор, конечно, вырос, по сравнению со временами СССР, но реальное производство оказалось просто разгромлено...

Грей вполне конкретно объясняет, почему «чистый», или «старый», либерализм в экономической сфере уже является утопией. Причина - «свободный» рынок не обеспечивает необходимой социальной стабильности $[5$, с. 203].

По справедливому замечанию известного политического теоретика, одной из фундаментальных проблем является то, что теоретики либеральной идеи не желают осмысливать просчеты и проблемы данного политико-правового учения и тем самым реализовать универсальность ratio: «Провалы проекта Просвещения, служащие мне отправной точкой анализа, являются и интеллектуальными, и историческими, хотя интеллектуальные просчеты традиционное либеральное мышление вытесняет из поля зрения: я имею в виду неспособность либеральных теоретиков выполнить важнейшее обещание проекта Просвещения и обосновать принципы либерального общества универсальными требованиями разума» [5, с. 134].

Именно осознания ratio не хватило организаторам «перестройки», следствием которой и стал хаос в экономике и управлении, который затем привел к распаду огромного государства. Конечно, само наличие замысла проведения реформ в Советском Союзе, осознание их насущной необходимости представляло явление, безусловно, позитивное. В этом смысле руководители Советского государства рассуждали абсолютно правильно. Но исполнение оказалось просто отвратительным, радикально далеким от благих намерений и радужных ожиданий. Можно сказать и по-другому - сценарий был идеальный, очень хороший, а сыграли актеры-управленцы так, что смысл пьесы изменился кардинально. И вместо «перестройки» общесоциального здания, Отечества, случилось даже не разрушение его, а бессмысленное обрушение. Самое поразительное, что для первого лица в государстве это оказалось полной неожиданностью. Примечательно, что такое наивное представление об окружающем мире не ускользнуло от внимательного взгляда крупнейших мировых политиков. Маргарет Тэтчер, например, весьма откровенно оценивала уровень политической прозорливости последнего советского лидера: «Михаил Горбачев положил начало реформам в Советском Союзе, которые привели - хотя и неожиданно для него (выделено мной. - В. Б.) - к крушению коммунизма» $[20$, c. 30$]$.

\section{Выводы}

Решение «общих дел», построение процветающего, справедливого государства невозможно без публично-правового регулирования экономических отношений. При этом частный интерес не подавляется, а получает гарантии развития. В современном мире, развивающемся в условиях глобализации, значение публично-правового регулирования экономической деятельности не только не утрачивает своего значения, а приобретает все большую актуальность.

Современное понимание социального государства диктует и соответствующее осмысление либеральной идеологии. Роль государства в экономике не должна сводиться к функции «ночного сторожа». Вмешательство государства в экономику на деле приводит не к уменьшению, а к расширению свободы индивида.

Публично-правовое регулирование экономических отношений приобретает особое значение в период проведения экономических реформ. Именно публичная власть служит основным гарантом их надлежащей реализации. 
B.Э. Березко. Публично-правовое регулирование экономических отношений в современном государстве

\section{ПРИМЕЧАНИЯ}

1 Его сущность с максимальной точностью выразил известный российский правовед М.А. Исаев: «Самая острейшая форма социального вопроса звучит так: как прожить на одну зарплату? Понятно, что для некоторых категорий работников этот вопрос давно и окончательно решен, но для большинства лиц наемного труда это острейший вопpoc...» [8, с. 940]. О сущности социального вопроса также в свое время прекрасно высказался известный немецкий правовед Лоренц фон Штейн (см. подробнее: [27, с. 572]). Интересны в этой связи и выводы известных дореволюционных российских юристов, например М.М. Ковалевского [12, с. 31].

2 «Отравляющее влияние денег - жгучее желание извлечь прибыль из каждого капиталовложения - и вытекающее отсюда пренебрежение кработе и к принципу служсения (выделено мной. - В. Б.) не раз представали передо мной в самых разнообразных формах. Они - корень всех проблем» [21, с. 59].

${ }^{3}$ В свое время московский градоначальник Юрий Михайлович Лужков так писал по этому поводу: «Парадокс истории, как это часто бывает, заключается в том, что она нас ничему не учит. Нынешние российские либерал-реформаторы оказываются в полном смысле слова последовательными “большевиками-ленинцами”...» [14, с. 13].

\section{СПИСОК ЛИТЕРАТУРЫ}

1. Атаманчук, Г. В. Государство, государственное управление, государственный аудит в Российской Федерации (сущность явлений и механизмы их реализации) : монография / Г. В. Атаманчук, С. В. Степашин, С. М. Шахрай. - М. : [б. и.], 2012. $-576 \mathrm{c}$.

2. Атаманчук, Г. В. Сущность государственной службы: история, теория, закон, практика : монография / Г. В. Атаманчук. - М. : РАГС, 2008. - 310 с.

3. Атаманчук, Г. В. Теория государственного управления : учебник / Г. В. Атаманчук.-М. : Омега-Л, 2010. - 525 с.

4. Глаголев, В. С. Модальность в праве: различия культурных контекстов / В. С. Глаголев // Право и управление. XXI век. - 2018. - № 3. - С. 21-28.

5. Грей, Д. Поминки по Просвещению: политика и культура на закате современности / Д. Грей. М. : Праксис, 2003. - 368 с.

6. Енгибарян, Р. В. Многоликая демократия: время переоценки ценностей / Р. В. Енгибарян // Международная жизнь. - 2017. - № 9. - С. 90-98.

7. Завьялова, Е. Б. Корпоративная социальная ответственность / Е. Б. Завьялова, Ю. К. Зайцев, Н. В. Студеникин. - М. : Юрайт, 2017. - 125 с.
8. Исаев, М. А. История государства и права зарубежных стран / М. А. Исаев. - М. : Юрайт, 2012.

9. Катасонов, В. Ю. Военная сила доллара. Как защитить Россию / В. Ю. Катасонов. - М. : Алгоритм, 2015. $-238 \mathrm{c}$.

10. Катасонов, В. Ю. Мировая кабала. Ограбление по... / В. Ю. Катасонов. - М. : Алгоритм, 2015.

11. Катасонов, В. Ю. Экономика Сталина / В. Ю. Катасонов. - М. : Институт русской цивилизации, 2014. $-416 \mathrm{c}$.

12. Ковалевский, М. М. Прогресс / М. М. Ковалевский // Ковалевский М. М. Избранные труды. В 2 ч. Ч. 2. - М. : РОССПЭН, 2010. - 445 с.

13. Кревельд, М. ван. Расцвет и упадок государства : пер. с англ. / М. ван Кревельд. - М. : ИРИСЭН, 2006. - 542 с.

14. Лужков, Ю. М. Развитие капитализма в России. 100 лет спустя / Ю. М. Лужков. - М. : Минэлла, 2005.

15. Новгородцев, П. И. Введение в философию права. Кризис современного правосознания / П. И. Новгородцев. - М. : Наука, 1996. - 269 с.

16. Новгородцев, П. И. Об общественном идеале / П. И. Новгородцев. - М. : Пресса, 1991. - 640 с.

17. Ориу, М. Основы публичного права : пер. с фр. / М. Ориу. - М. : Изд-во Коммунистической академии, 1929. $-759 \mathrm{c}$.

18. Охотский, Е. В. Государственный служащий: статус, профессия, призвание / Е. В. Охотский. - М. : Экономика, 2011. - 701 с.

19 Селигмен, Б. Основные течения современной экономической мысли / Б. Селигмен. - М. : Прогресс, 1968. - 600 с.

20. Тэтчер, М. Искусство управления государством: стратегии для меняющегося мира : пер. с англ. / М. Тэтчер. - М. : Альпина Паблишер, 2012. - 504 с.

21. Форд, Г. Моя жизнь, мои достижения / Г. Форд. - Минск : Попурри, 2011. - 350 с.

22. Хайек, Ф. А. Дорога к рабству / Ф. А. Хайек. - М. : Новое издательство, 2005. - 264 с.

23. Хайек, Ф. А. Индивидуализм и экономический порядок/Ф. А. Хайек. - М. : Изограф, 2001. -256 c.

24. Хайек, Ф. А. Контрреволюция науки. Этюды о злоупотреблениях разумом / Ф. А. Хайек. М. : Фонд «Либеральная миссия», ОГИ (Объединенное гуманитарное издательство), 2003. - 288 с.

25. Хайек, Ф. А. Пагубная самонадеянность. Ошибки социализма / Ф. А. Хайек. - М. : Новости, 1992. $-304 \mathrm{c}$.

26. Чичерин, Б. Н. Собственность и государство / Б. Н. Чичерин. - М., 2010.

27. Штейн, Л. Учение об управлении и право управления с сравнением литературы и законодательств Франции, Англии и Германии : Руководство : пер. с нем. / Л. Штейн. - СПб. : А.С. Гиероглифов, 1874. -594 с. 
28. Эрхард, Л. Благосостояние для всех : пер. с нем. / Л. Эрхард. - М. : Начала-Пресс, 1991. - 332 с.

\section{REFERENCES}

1. Atamanchuk G.V., Stepashin S.V., Shakhray S.M. Gosudarstvo, gosudarstvennoe upravlenie, gosudarstvennyy audit $v$ Rossiyskoy Federatsii (sushchnost yavleniy i mexanizmy ikh realizatsii) [State, Public Administration, State Audit in Russia (The Essence of Phenomena and Implementation Mechanism)]. Moscow, 2012.576 p.

2. Atamanchuk G.V. Sushchnost gosudarstvennoy sluzhby: istoriya, teoriya, zakon, praktika: monographiya [The Essence of Public Service: History, Theory, Law, Practice: Monograph]. Moscow, RAGS Publ., 2008.310p.

3. Atamanchuk G.V. Teoriya gosudarstvennogo upravleniya: uchebnik [Theory of Public Administration]. Moscow, Omega-LPubl., 2010. 525 p.

4. Glagolev V.S. Modalnost v prave: razlichiya kulturnykh kontekstov [Modalityin Law: Cultural Contexts Differences]. Pravo i upravlenie. XXI vek [Journal of Law and Administration], 2018, no. 3, pp. 21-28.

5. Grey D. Pominki po Prosveshcheniyu: politika i kultura na zakate sovremennosti [Funeral Repast on the Age of the Enlightenment: Politics and Culture in the Decline of Modern Times]. Moscow, Praksis Publ., 2003. 368 p.

6. Engibaryan R.V. Mnogolikaya demokratiya: vremya pereotsenki tsennostey [Multifaceted Democracy - It's Time to Re-evaluate Values]. Mezhdunarodnaya zhizn [International Affairs], 2017, no. 9, pp. 90-98.

7. Zavyalova E.B., Zaytsev Yu.K., Studenikin N.V. Korporativnaya sotsialnaya otvetstvennost: uchebnik dlya bakalavriata i magistratury [Corporate social responsibility: a textbook for undergraduate and graduate]. Moscow, Yurayt Publ., 2017. 125 p.

8. Isaev M.A. Istoriya gosudarstva i prava zarubezhnykh stran [History State and Law of Foreign Countries]. Moscow, Yurayt Publ., 2012.

9. Katasonov V.Yu. Voennaya sila dollara. Kak zashchitit Rossiyu [Military Force of Dollar. What can we do in order to protect Russia]. Moscow, Algoritm Publ., 2015. 238 p.

10. Katasonov V.Yu. Mirovaya kabala. Ograblenie po... [World Bondage. Robbery according to...]. Moscow, Algoritm Publ., 2015.

11. Katasonov V.Yu. Ekonomika Stalina [Stalin's Economy]. Moscow, Institut russkoy tsivilizatsii, 2014. $416 \mathrm{p}$.

12. Kovalevskiy M.M. Progress [Progress]. Izbrannye trudy. V2 ch. Ch. 2 [Selected Works. In 2 vols. Vol. 2]. Moscow, ROSSPEN Publ., 2010. 445 p.
13. Kreveld M. van. Rastsvet $i$ upadok gosudarstva [Prosperity and Decline of State]. Moscow, IRISEN, 2006. 542 p.

14. Luzhkov Yu.M. Razvitie kapitalizma v Rossii. 100 let spustya [Development of Capitalism in Russia. One Hundred Years Later]. Moscow, Minella Publ., 2005.

15. Novgorodtsev P.I. Vvedenie $v$ filosofiyu prava. Krizis sovremennogo pravosoznaniya [Philosophy of Law Introduction]. Moscow, Nauka Publ., 1996. 269 p.

16. Novgorodtsev P.I. Ob obshchestvennom ideale [About Public Ideal]. Moscow, Pressa Publ., 1991. 640 p.

17. Oriu M. Osnovy publichnogo prava [Foundation of Public Law]. Moscow, Izd-vo Kommunisticheskoy akademii, 1929. 759 p.

18. Oxotskiy E.V. Gosudarstvennyy sluzhashchiy: status, professiya, prizvanie [State Official: Status, Profession, Mission]. Moscow, Ekonomika Publ., 2011. 701 p.

19. Seligmen B. Osnovnye techeniya sovremennoy ekonomicheskoy mysli [Basic Trends of Modern Economic Thought]. Moscow, Progress Publ., 1968. 600 p.

20. Tetcher M. Iskusstvo upravleniya gosudarstvom: strategii dlya menyayushchegosya mira [Art of Government: Strategy for Varying World]. Moscow, Alpina Publ., 2012. 504 p.

21. Ford G. Moya zhizn, moi dostizheniya [My Life and My Gains]. Minsk, Popurry Publ., 2011. 350 p.

22. Xayek F.A. Doroga $k$ rabstvu [The Way to Slavery]. Moscow, Novoe izd-vo, 2005. 264 p.

23. Xayek F.A. Individualizm i ekonomicheskiy poryadok [Individualism and Economic Order]. Moscow, Izograph Publ., 2001. 256 p.

24. Xayek F.A. Kontrrevolyutsiya nauki. Etyudy o zloupotrebleniyakh razumom [Counter-Revolution of Science. Studies about Mind Abuse]. Moscow, Fond «Liberalnaya missiya», OGI (Obedinennoe gumanitarnoe izdatelstvo), 2003. 288 p.

25. Xayek F.A. Pagubnaya samonadeyannost. Oshibki sotsializma [Destructive Presumption. Mistakes of Socialism]. Moscow, Novosty Publ., 1992. 304 p.

26. Chicherin B.N. Sobstvennost i gosudarstvo [Property and State]. Moscow, 2010.

27. Shteyn L. Uchenie ob upravlenii i pravo upravleniya s sravneniem literatury i zakonodatelstv Frantsii, Anglii i Germanii: Rukovodstvo : per. s nem. [The Authority Doctrine and Authority Law with the Comparison of French, English and German Literature and Legislation. Guidelines. Translated from German]. Saint Petersburg, 1874. 594 p.

28. Erkhard L. Blagosostoyanie dlya vsekh [General Welfare]. Moscow, Nachala-Press, 1991. $332 \mathrm{p}$. 
B.Э. Березко. Публично-правовое регулирование экономических отношений в современном государстве

\section{Information about the Author}

Vladimir E. Berezko, Candidate of Sciences (Jurisprudence), Associate Professor, Department of Public Administration, Moscow State Institute of International Relations of the Ministry of Foreign Affairs of the Russian Federation, Prosp. Vernadskogo 76, 119454 Moscow, Russian Federation, vberezko@yandex.ru, https://orcid.org/0000-0003-4857-8883

\section{Информация об авторе}

Владимир Эдуардович Березко, кандидат юридических наук, доцент кафедры государственного управления, Московский государственный институт международных отношений (Университет) МИД России, просп. Вернадского, 76, 119454 г. Москва, Российская Федерация, vberezko@yandex.ru, https://orcid.org/0000-0003-4857-8883 